\title{
Elogio de Don Carlos Tünnermann Bernheim: un diamante de nuestra cultura
}

\section{(Presentación de la Obra Valoración Múltiple)}

${ }^{1}$ Por Anastasio Lovo

\author{
(...) la obra profunda de la hora, \\ la labor del minuto y el prodigio del año. \\ Rubén Darío
}

Recibido: 26 de abril de 2013 / Aprobado: 18 de junio de 2013.

$\mathrm{E}$ s muy difícil para cualquiera aquilatar un diamante en vivo como resulta ser la trascendente labor cultural de Don Carlos Tünnermann Bernheim, en 80 fructíferos años. Podemos quedarnos con su lucidez cegadora y hacerlo faro en los grandes temas sobre la universidad y la educación que lo han ocupado; disfrutar y aprender de la pulcritud y profundidad de su prosa en sus estudios darianos; gozar la economía y transparencia de sus versos; o plantearse seriamente cimentar una cultura política nacional a partir de su imperturbable y magistral firmeza ética. Esta labor de ponderación la hace la comunidad nacional al paso del tiempo, no es trino de ave solitaria, sino coro de hermosas voces.

Así lo dice muy bien el Maestro Ernesto Cardenal en sus Palabras introductorias en Homenaje nacional a un héroe cívico: "Valorar a Carlos Tünnermann no es tarea fácil ni es tarea de una o dos personas solamente, porque tiene múltiple valores".

En atención a esa necesidad, esta noche me cabe el inmenso honor de presentar la obra colectiva Valoración Múltiple, Opiniones sobre la obra educativa y literaria de Carlos Tünnermann Bernheim, En ocasión de sus 80 años de vida y 55 de trayectoria académica, (Academia Nicaragüense de la Lengua, Managua, 2013).

1 Escritor y crítico de arte nicaragüense, Coordinador del Área de Cultura de Paz del Instituto "Martin Luther King"-UPOLI, Presidente del Centro Nicaragüense de Escritores (CNE)

\section{RESUMEN}

En este Elogio de Don Carlos Tünnermann Bernheim, el escritor Anastasio Lovo, hace una valiosa reseña de la monumental obra del Maestro estudiada por varios autores en el libro Valoración Múltiple. Lovo satura en su análisis los niveles de producción textual de Carlos Tünnermann desde el punto de vista de una labor cultural cuyos núcleos sobresalientes son: la educación global, la universidad, los estudios literarios y darianos, la labor arqueológica y su escritura poética.

Palabras clave: ética, valores, pensador humanista, disciplina, universal.

\section{ABSTRACT}

The writer Anastasio Lovo, in this "Don Carlos Tünnermann Bernheim's praise", makes a valuable review of the monumental work of the Master, which it has been studied by several authors in the book "Multiple Evaluation". Lovo in his analysis saturates the textual production levels by Carlos Tünnermann from the point of view of a cultural work whose core features are: global education, university, and literary and darianos studies, archaeological work and poetic writing.

Key words: ethics, values, humanist thinker, discipline, universal. 


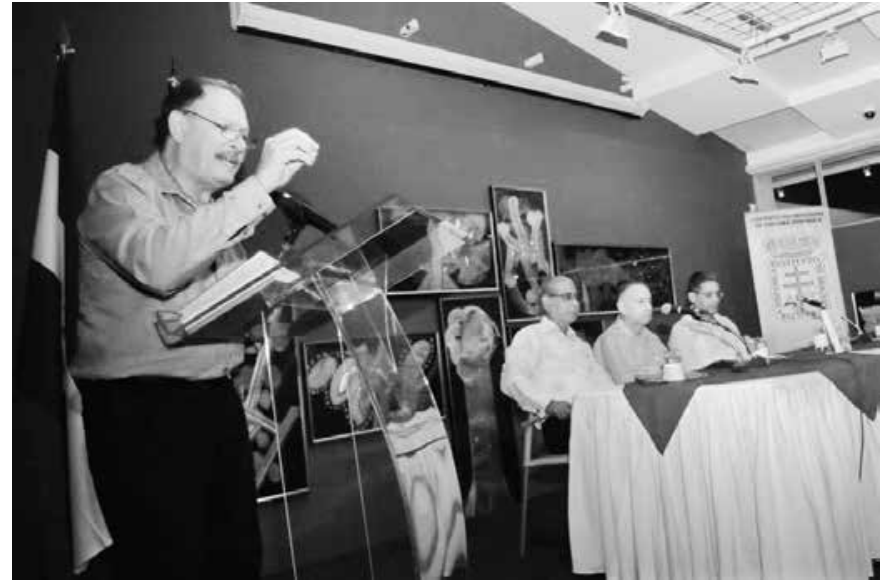

EL Lic. Anastasio Lovo, Presidente del Centro Nicaragüense de Escritores, en la presentación del libro "Valoración Múltiple - Opiniones sobre la obra educativa y literaria de Carlos Tünnermann Bernheim".

Valoración Múltiple está constituida por una valiosa selección de abordajes críticos, ensayos, semblanzas, artículos, poemas que ha provocado en muchos elevados espíritus de nuestra comunidad nicaragüense, latinoamericana y mundial, a lo largo del tiempo la obra del Maestro Don Carlos Tünnermann Bernheim.

Con este texto se pretende abrir la riquísima veta de los estudios de una obra trascendental, prolífica, de muy amplio espectro genérico y pertinente en lo social, como lo es, ha sido y será la extraordinaria labor cultural del nicaragüense Carlos Tünnermann Bernheim, a quien hoy nos honramos en festejar sus 80 magníficos años y 55 de trayectoria académica. Don Carlos Tünnermann Bernheim, diamante vivo de nuestra cultura latina del cual esta noche, veremos la luz de algunas de sus facetas. Valoración Múltiple Opiniones sobre la obra educativa y literaria de Carlos Tünnermann Bernheim, (Academia Nicaragüense de la Lengua, Managua, 2013), está estructurada en cuatro significativos capítulos: I. Semblanzas y reconocimientos; II. Opiniones sobre las obras educativas; III. Opiniones sobre las obras literarias; IV. Poesía: Este capítulo trae poemas de Carlos Martínez Rivas, Francisco Arellano Oviedo y Federico Mayor Zaragoza. Valoración múltiple después de los capítulos indicados, también contiene un Anexo y una Galería de Fotos. En su portada hay un logrado retrato al grafito de nuestro insigne doctor Tünnermann plasmado por la diestra mano del maestro Julio Martínez.

Es recomendable, por razones de método de exposición, que nos aproximemos a la labor cultural del Doctor
Carlos Tünnermann Bernheim, desde una perspectiva de su ser íntegro: un pensador humanista y un poeta. En el primer capítulo de este libro Semblanzas y reconocimientos vamos encontrar algunos párrafos que intentan dar cuenta de esta totalidad desde una óptica de águila cenital.

El Doctor Justo Pedro Castellanos, Rector de la UNAPEC de Santo Domingo República Dominicana, distingue lo siguiente a propósito de Tünnermann: "Pensador, teórico y escritor, uno de los más prolíficos, profundos e importantes de su país; fuera de él, a menudo se le ve codearse con sus semejantes, los grandes del pensamiento mundial: Federico Mayor Zaragoza, Edgard Morin y Jacques Delors."

O como se afirma en el Acuerdo del Consejo Ejecutivo de la Unión de Universidades de América Latina (UDUAL) al otorgar al Doctor Carlos Tünnermann Bernheim el Premio “Doctor Carlos Martínez Durán" 2004: "Carlos Tünnermann Bernheim es uno de los intelectuales más sólidos de nuestro continente y un orgullo para América Latina por toda su labor de construcción y consolidación de la democracia política como sistema de convivencia y de una cultura de paz como utopía a realizar por un mundo mejor."

Por su parte, la Doctora Carmen Evaristo Matías, Decana de la Facultad de Humanidades de la Universidad Autónoma de Santo Domingo, República Dominicana, aborda esta totalidad del Doctor Tünnermann de la siguiente manera, cito: "No se sabe que es más grande en él, si su alma de poeta o su reciedumbre intelectual. En él se conjugan estas dos grandes dimensiones que hacen del Doctor Tünnermann una persona con condiciones excepcionales, comparado con los grandes hombres que han sabido vivir y luchar por la independencia, la democracia de su amada patria, por la mejor causa de la Educación Superior y en especial la cultura nicaragüense." En palabras del Doctor Mariano Defilló Ricart, Rector de la Universidad Nacional "Pedro Henríquez Ureña" de Santo Domingo, República Dominicana la totalidad del ser Tünnermannn es percibida así: "Abogado de los derechos humanos, propiciador y divulgador de una cultura de paz, profesor de profesores, maestro de maestros, (rector de rectores), don Carlos, el hombre que en cada arista del bien, del saber, del espíritu, de la sociedad y de nuestros pueblos, es un paradigma para todos los que conformamos la América hispana." 
A estas valoraciones aquila ópsis, me gustaría citar un párrafo del Maestro Sergio Ramírez Mercado, quien con sus dotes narrativas nos entrega una imagen ética y también cinemática de este incansable motor cultural que es Don Carlos, cito: "En el CSUCA recibí de Carlos otra enseñanza no menos valiosa que aquella del justo sentido del derecho: trabajar con disciplina, con rigor, y con sentido de la responsabilidad. Esa palabra workalcoholic o fue inventada por él, o la inventaron para él. Siempre yendo de una oficina a otra con paso rápido y nervioso para llamar a un colaborador, dictar una carta, dar una instrucción, atender el teléfono, o afilar él mismo el haz de lápices de grafito con que llenaba sus libretas o escribía sus informes o cartas. Su eficiencia, su virtud de organizador, su propiedad de cumplir las tareas a tiempo, no muy comunes en Centroamérica, se volvieron legendarias."

Para continuar en este capítulo deseo esta noche compartir con Ustedes, las memorables palabras de otro paradigma de la cultura nicaragüense, Don Pablo Antonio Cuadra quien sobre el ser poético y pensador de Don Carlos, en su discurso de recepción de Tünnermann en la Academia de la Lengua Española, afirmó lo siguiente: “ ¡Doctor Tünnermann, cuídese, usted lleva adentro un poeta! Y, ciertamente, llevaba al poeta en el mejor sentido, en el griego en que "poiesis" significa "creador", pues nuestro nuevo académico -itodos somos testigos!- ha ido creando o modelando la personalidad del PENSADOR, con figura escasa en nuestro medio (habladores nos sobran, pensadores nos faltan), es decir saber considerar, reflexionar, meditar y valorar sobre el acontecimiento, separar analíticamente sus componentes -el bien y el mal, lo superficial y pasajero, lo profundo y permanente- para que el pueblo sepa pesar, sopesar (de pesar viene pensamiento), lo que hace y debe hacer para su propia historia con dignidad y destino."

El segundo capítulo de Valoración múltiple contiene las ponderaciones y opiniones de estudiosos del tema sobre su magna obra educativa. Aquí podemos apreciar como la luz diamantina que de su obra dimana, se refleja en ojos y mentes acuciosas y penetrantes que hacen una lectura enriquecedora y singular de los aportes del Doctor Carlos Tünnermann Bernheim en este campo.

Se confronta la labor iluminadora de Carlos Tünnermann Bernheim sobre la universidad, todo un tema de donde se derivan sub temas axiales que nos enseñan sobre la universidad como teoría y praxis transformadora; la historia misma de la universidad mundial y latinoamericana; el discurrir y el discurso universitario que nos devela y evidencia estructuras y funciones de la misma; más la prospectiva futurista de este ente supremo de la cultura humana: la universidad.

Como afirma la Dra. Mayra Luz Pérez Díaz, Rectora de la Universidad Centroamericana UCA, en su Presentación del Doctor Carlos Tünnermann en ocasión de dictar la lección inaugural 2011: "Pocas personas han perfilado de manera tan evidente, hasta la esencia misma de su ser intelectual y espiritual, el concepto de hombre universitario como el Dr. Carlos Tünnermann Bernheim. Nacido en Nicaragua y renacido para el mundo, el Dr. Tünnermann es, ciertamente, un nicaragüense universal que ha proyectado su figura durante muchos años, especialmente desde el ámbito de la universidad, vivenciándola y analizándola como institución, como organización y como comunidad educativa, a través de

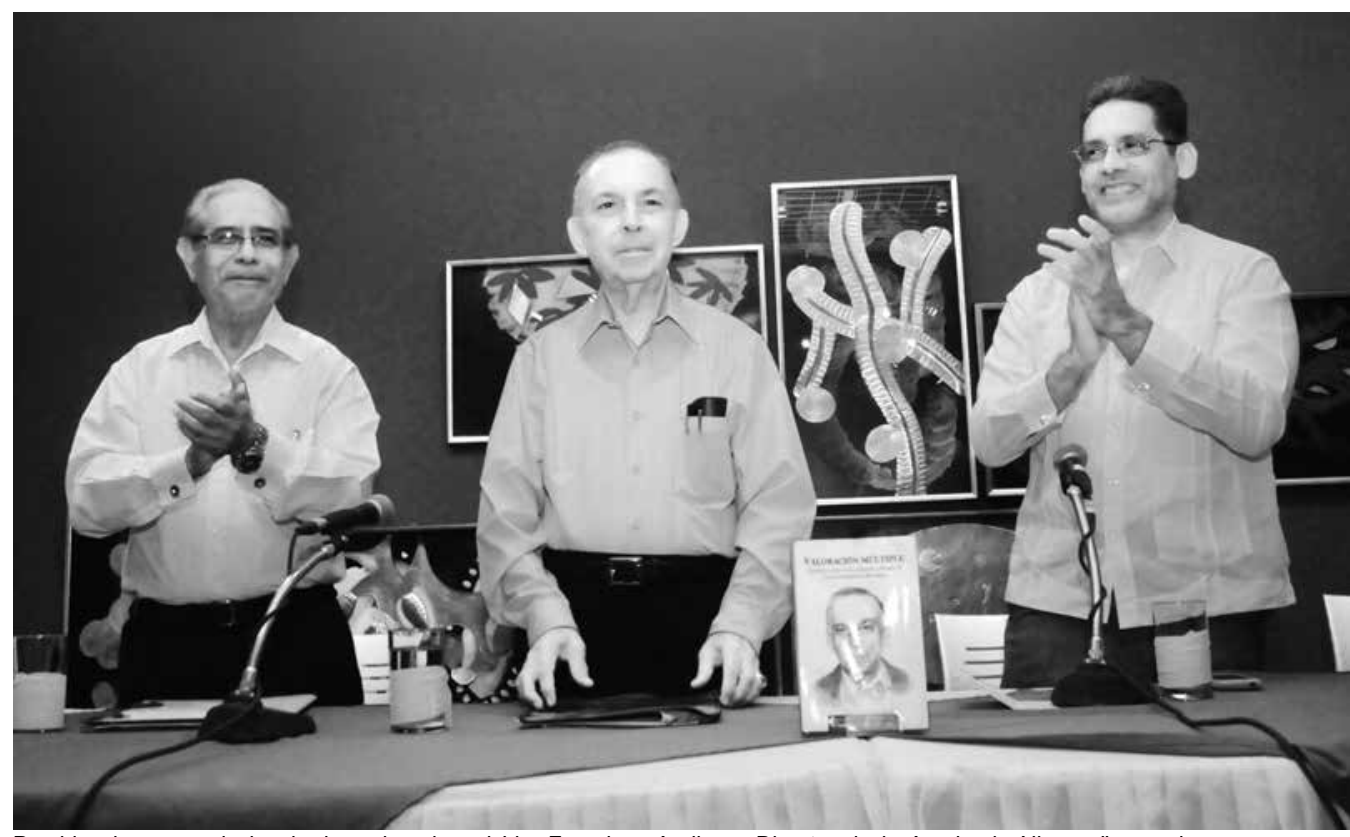

Presiden la mesa, de izquierda a derecha, el Lic. Francisco Arellano, Director de la Academia Nicaragüense de la Lengua; el Dr. Carlos Tünnermann y el Ing. René González, Presidente del Instituto Nicaragüense de Cultura Hispánica (INCH). 
una importante producción intelectual que trasciende este ámbito y que a la vez, es un reflejo del mismo."

En palabras del Maestro Edelberto Torres Espinoza, en una carta que le dirigiera al doctor Tünnermann encontramos este aserto sobre su personalidad y labor educativa: "Sin proponérselo, puesto que la modestia es característica de su personalidad y ella está presente en su obra, ha hecho usted su propia etopeya, y así se destaca como el trabajador intelectual que hace de la cultura el menester cotidiano, la rutina del cerebro y el corazón; como paradigma del universitario identificado con su función civilizadora."

La extraordinaria obra del Doctor Carlos Tünnermann Bernheim referida a la universidad reviste características de totalidad en lo que a este subsistema le corresponde, pero la labor pedagógica se resuelve en un ámbito más amplio: el de la educación como laborem excelsis. Es decir para Tünnermann, el gran marco teórico de su obra es la educación y el humanismo. Una educación concebida y practicada como revolucionaria y para la cual la labor del Maestro no ha dejado subsistema educativo sin teorizar, transformar, proponer y prever.

El maestro y Doctor Juan Bautista Arríen ponderando esta labor la devela nítidamente en este par de párrafos de su ensayo Carlos Tünnermann, educador, cito: "Carlos

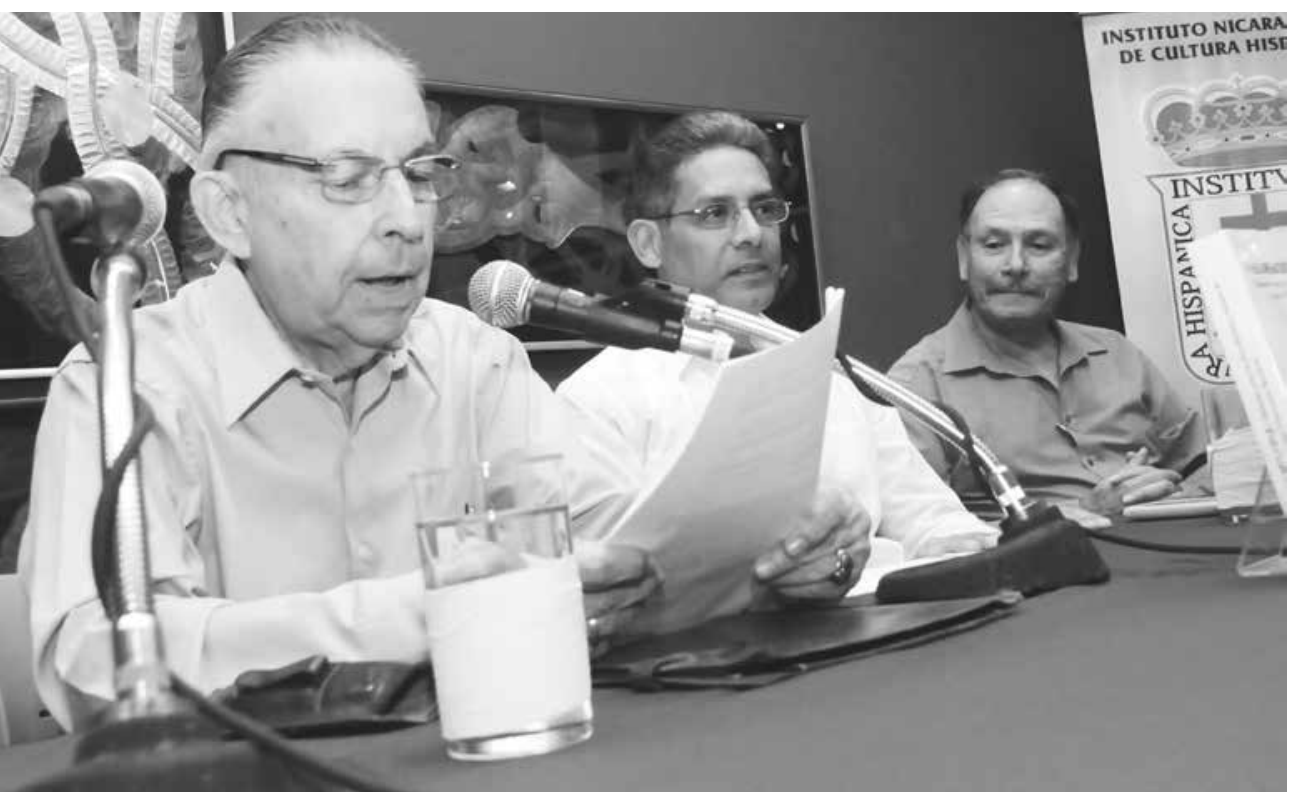

El Dr. Carlos Tünnermann Bernheim dirigiéndose a la audiencia. Al centro el Ing. René González, Presidente del Instituto Nicaragüense de Cultura Hispánica (INCH) y a la extrema derecha el Lic. Anastasio Lovo, Presidente del Centro Nicaragüense de Escritores.
(...) se ha convertido en maestro de la cultura educativa nacional y en el constructor más influyente de la educación moderna de nuestro país. Estas dos dimensiones, la de maestro de la cultura educativa y constructor de la educación moderna, han dejado de sentir su acción e impacto más allá de nuestras fronteras para atravesar las innovaciones educativas de otros países, especialmente, latinoamericanos.

El papel de Carlos educador, es el de ayudar a construir la educación como proceso sistemático e intencionado que deviene en un sistema educativo por cuanto su aporte se ubica en la conformación del aparato educativo global del país. Carlos es un arquetipo de la educación en cuyo espacio toma vida el proceso educativo de miles y miles de ciudadanos. Como constructor su aporte más significativo se sitúa principalmente en las grandes ideas de políticas educativas, los grandes principios y objetivos de la educación, las grandes orientaciones educativas de un país, los lineamientos fundamentales para organizar los sistemas educativos, la definición de exigencias y dirección de las grandes reformas educativas que adquieren su verdadero sentido cuando éstas se concentran en relaciones pedagógicas. El papel de Carlos educador hace del todo educativo el eje fundamental de su acción."

Por su parte el Doctor Enrique Agüera Ibáñez, Rector de la Benemérita Universidad Autónoma de Puebla, México, en ocasión de otorgarle el doctorado honoris causa al Maestro Tünnermann, señaló: “Carlos Tünnermann reúne las cualidades del maestro e intelectual dedicado a explorar las posibilidades educativas en nuestro continente, con un objetivo primordial: la construcción de una sociedad más próspera, justa y solidaria, basada en un modelo de desarrollo humano sustentable que fortalezca las identidades culturales, favorezca la cohesión social y promueva una cultura de paz."

Para el Doctor Luis Manuel Peñalver en su ensayo El doctor Carlos Tünnermann y su estudio sobre la reforma

Continúa en la página 25 
de Córdoba, presidente de GULERPE y de FEDES, la visión es la siguiente: "(...) Carlos Tünnermann no ha sido un académico encerrado en actitudes y conceptos de torre de marfil, sino que ha sabido interpretar el trasfondo político social del fenómeno educativo y especialmente del universitario. Y hasta vivir, con ánimo decidido y valiente, dramáticas incidencias del complejo proceso en que han venido siendo actores las Universidades del Continente."

Sobre este sentido de la historia en Carlos Tünnermann referidas a la universidad y a la educación, el Padre Xavier Gorostiaga S.J. (QEPD), a la sazón (1992) Rector de la UCA en su prólogo al libro "Universidad: historia y reforma", señala: "La reflexión histórica sobre las Universidades que nos presenta el Dr. Carlos Tünnermann no es un mero trabajo teórico o histórico abstraído de la problemática actual. Constantemente Carlos Tünnermann levanta los temas conflictivos en la fundación de las Universidades teniendo como trasfondo la problemática a la que éstas se enfrentan en el día de hoy, y en especial a la problemática a la que se enfrenta la Universidad en Nicaragua."

Acerca del aspecto prospectivo de la universidad del futuro, el Doctor Luis Yarzábal (Director del CRESALC/ UNESCO Caracas, Venezuela), en su prólogo al libro de Tünnermann, La Educación superior en el umbral del siglo XXI, nos aclara que: "En ellos el autor, una de las personalidades más prestigiosas en lo que tiene que ver con los aspectos históricos, teóricos y prácticos de la educación superior, analiza los orígenes y la evolución de las universidades; describe la progresiva instalación y adaptación de estas instituciones al ámbito latinoamericano; presenta una nueva visión de la educación superior que requiere la región; destaca el papel de ese nivel educativo en el proceso de integración de América Latina y el Caribe; y expone las características que, a su juicio, debe tener la universidad del Siglo XXI."

En el prólogo del Maestro Francisco López Segrera, Consejero Regional de la UNESCO en Ciencias Sociales, al libro de Don Carlos, Los derechos humanos: evolución histórica y reto educativo, vemos como se imbrican transdisciplinariamente los paradigmas educativos con derechos humanos y cultura de paz: "El libro de Carlos Tünnermann, que logra tejer una maravillosa urdimbre con la visión transdisciplinaria de la totalidad propia del pensamiento complejo, -derechos humanos, medio ambiente, cultura de paz...- aboga por un nuevo contrato moral (y por ende social) de la sociedad en vísperas del siglo XXI, que evite -vía una cultura de paz- que el cambio de siglo y milenio implique seguir construyendo un telos apocalíptico."

Mención especial merece dentro de esta obra el ensayo del Doctor Miguel de Castilla Urbina, intitulado Carlos Tünnermann y su Universidad y Sociedad (autor y obra en permanente ciclo ascendente), de éste me gustaría citar un par de párrafos que nos ayuden a completar la dimensión de esta obra y si acaso, poder armar teselas de la poderosa imago de este pater cultural que es para los nicaragüenses y latinoamericanos, Don Carlos Tünnermannn Bernheim. Dice Miguel: "En Carlos Tunnermann no se trata del profesional tecnocrático y sectorial, especialista en aspectos puntuales y específicos del quehacer universitario, como lo serían aspectos relacionados con
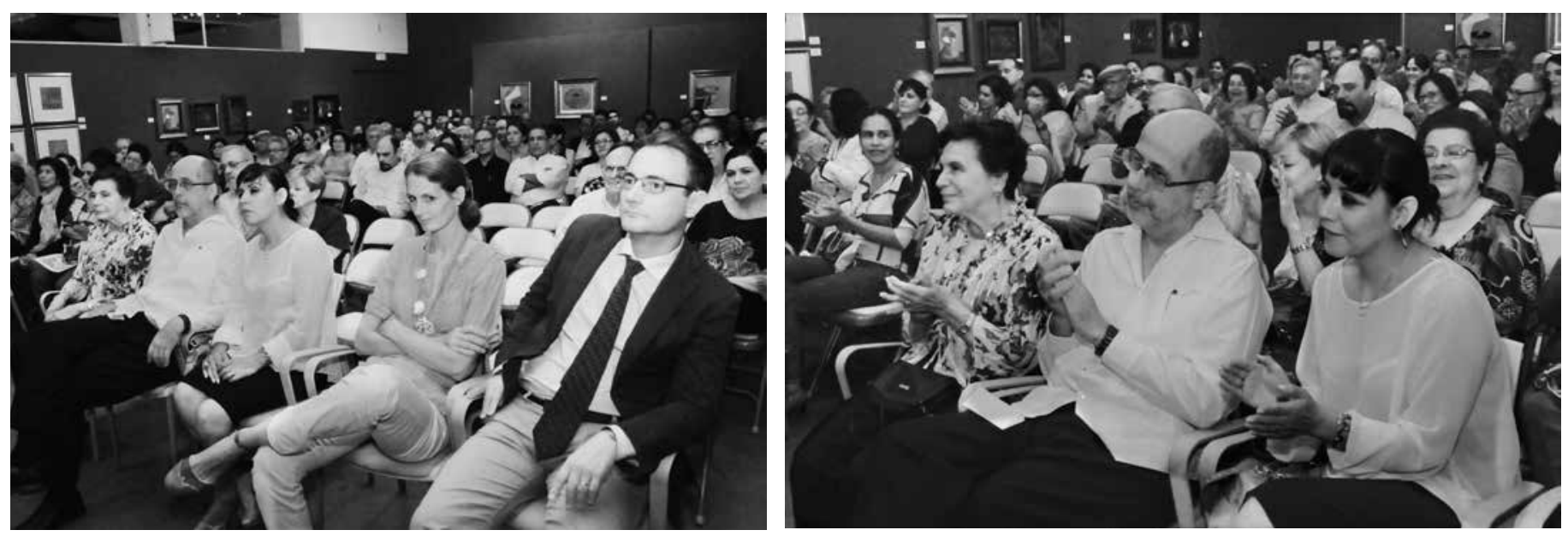

Público asistente al acto de presentación del Libro Valoración Múltiple, el 25 de abril de 2013 en el INCH. 
la administración de recursos, modelos académicos, pedagogía y didáctica, planificación, curriculum, evaluación de la calidad, formulación de políticas científicas y de investigación, extensión, acción social y autonomía universitaria. No, en Carlos se trata, del experto global en la Universidad, en toda la Universidad, en todos sus subsistemas, funciones y procesos, en todos sus vericuetos, escondrijos y resquicios.

(...) Haciendo abstracción de nuestros Ernesto Cardenal y Sergio Ramírez Mercado, no se si habrá otro nicaragüense vivo, hoy por hoy, experto en cualquier ciencia, materia, área, disciplina o tema de la cultura enciclopédica, del conocimiento y los saberes; en las ciencias naturales, las ciencias sociales, y las humanidades, con la estatura, el prestigio y la autoridad académica a nivel internacional, del nicaragüense Carlos Tunnermann Bernheim respecto al amplio y complejo mundo de la Educación Superior, profundamente citado en la actualidad en marcos de referencia teoría de tesis doctorales o en preámbulos de leyes sobre esta materia de países diferentes al suyo.

(...) Carlos ha hecho con su monumental obra sobre la institución conocida como Universidad hoy sintetizada en el libro Universidad y Sociedad, lo que Cortázar hizo con Rayuela, un modelo cuyas piezas aparentemente sueltas, caben y se articulan homogéneamente en una sola lógica y un solo discurso. Por eso es que es capaz de estudiar diacrónicamente el largo tránsito de la Universidad a través de su historia, para a su vez, sin mucho esfuerzo, concentrarse sincrónicamente en un período del mismo, o en la actualidad, y desde ahí separar sus partes para su estudio y análisis, conservando siempre su lenguaje y su enfoque uniforme, sistémico, holístico e integral.

(...) Para los universitarios nicaragüenses y latinoamericanos, interesados en aprender sobre la problemática universitaria y sobre la necesidad de la Reforma y Transformación de los Modelos Académicos y Administrativos de nuestras Universidades, aún sobre la necesidad de Reforma y Transformación de las Universidades Privadas, que recién acaban de nacer como copia al carbón de los viejos modelos académicos de las viejas universidades públicas de nuestros países, esta obra de Carlos Tunnermann Bernheim, es fundamental para pensar y hacer la Universidad del futuro y del mañana; del mañana que está aquí y es ahora."
Por otro lado mi colega, el Maestro Erwin Silva, se encarga de situar la perspectiva epistemológica en la obra de nuestro querido Doctor Tünnermann. Dice así en su Opinión sobre el libro Tendencias contemporáneas de la Educación Superior, cito: "Pero al referirnos a sus libros, debemos decir que encontramos en ellos numerosos aportes desde lo histórico y la conjugación de la epistemología, la educación y la pedagogía. O sea, hay todo un discurso humanista y un pensamiento pedagógico que es necesario analizar para el fortalecimiento de la formación en valores, la retroalimentación para el área metodológica, de las misiones y funciones de la Universidad nicaragüense y por supuesto para nuestro enriquecimiento personal como profesores universitarios."

El legado pedagógico de Carlos Tünnermann es sintetizado por el Maestro Cefas Asensio Flórez así: “De su legado hemos de decir que cuando sean los mismos desafíos de antaño, cuando se trate de retomar los orígenes de nuestra Universidad en Nicaragua, desde la colonia, el noble y vibrante espíritu de sus fundadores y luchadores por sus principios; o cuando se trate de retomar las revolucionarias y visionarias propuestas de la Reforma de Córdoba, allí nos acompañará la memoria y sistematización privilegiada que Carlos Tünnermann Bernheim nos ha legado. Al igual, que si se trata de un análisis contemporáneo de la calidad académica y la capacidad de respuesta social de nuestras universidades, cuando se trate de afrontar los grandes desafíos de la integración regional de las universidades, con visión de futuro, entre muchos otros grandes y trascendentales temas. Cuando necesitemos la responsabilidad del arquitecto y del constructor que edifica sobre la roca, no dudemos, no nos equivocaremos, tendremos en el legado del Doctor Carlos Tünnermann un nicho intelectual prolífico y certero desde donde realizar nuestra búsqueda permanente de la Universidad."

Veamos ahora del humanista Carlos Tünnermann Bernheim su luz literaria, su antorcha de letras, su luminosa e imborrable gramma. El tercer capítulo del texto Valoración Múltiple, muy acertadamente está dedicado a las Opiniones sobre las obras literarias escritas por el Doctor Carlos Tünnermann Bernheim.

El escritor Carlos Tünnermann Bernheim posee una pasión creativa, analítica, arqueológica, histórica, 
amorosa y lúdica por la literatura y sus diversas formas. Este poeta de corazón, crítico acucioso y académico de la lengua se ha ocupado de la historia, la teoría y la praxis del periodismo en Nicaragua; ha producido lúcidos ensayos sobre el magisterio de Rubén Darío y ha abordado con sapiencia y profundidad el análisis de las obras de destacados poetas y escritores de Nicaragua; también ha recibido el flechazo erótico de poiesis y nos ha entregado los cristalinos versos de Para construir el amor, su ya célebre y muy comentado libro de poemas.

Muy significativa, singular y productiva es la lectura que el filósofo Jorge Alvarado Pisani, nato venezolano pero nicaragüense de corazón, hace del libro de Tünnermann, León Viejo y otros escritos, en un certero ensayo que él tituló: "Un libro para subirnos la moral". Utilizando la hermeneútica, Alvarado Pisani alcanza a hacer una lectura de la labor arqueológica de Tünnermann entendida ésta como recuperación y puesta en vigencia de algunas genealogías de la cultura nicaragüense y latinoamericana. Sólo quiero citar un poderoso párrafo de este valioso escrito de Jorge Alvarado Pisani sobre este particular aspecto de la labor cultural de nuestro homenajeado.

Dice Alvarado Pisani: "El ensayo titular del libro, "León Viejo: historia y ruinas", documenta la bien probada voluntad arqueológica del Dr. Tünnermann, entendiendo la arqueología no sólo como disciplina científicotecnológica de descubrimiento, recuperación y exhibición de vestigios culturales sino como la actitud filosófica de retraer el pasado al presente para transformar el presente de cara al futuro. Nos demuestra allí Tünnermann, en prosa didáctica, la misma tesis que, en prosa poética, nos muestra Julio Valle-Castillo en su reciente novela Réquiem en Castilla del Oro. La historia y las ruinas de León Viejo no son sólo sucesos a orillas del Momotombo sino vivencias ocultas bajo la tierra y las cenizas de la conciencia histórica de Nicaragua. Hernández de Córdoba degollado, Pedrarias Dávila furibundo, Antonio de Valdivieso mártir, Hermano de Contreras desquiciado son carne y sangre (sangre, sobre todo sangre), pecado original y promesa redentora, de la condición histórica de nuestro país. En consecuencia, la construcción de una cultura de paz en Nicaragua pasa por el exorcismo de los demonios de Pedrarias y Contreras y por la invocación de los espíritus tutelares de nuestra patria-matria. Y ello no se logra relegándose al olvido sino exponiéndolos a la claridad. El empecinamiento de Tünnermann en sacar a la luz la historia y las ruinas de León Viejo es una tarea no sólo de arqueología física sino, fundamentalmente, de arqueología moral."

Sobre los estudios darianos de Tünnermann es memorable la opinión que de ellos tiene mi querido Maestro Don Guillermo Rothschuh Tablada, de cuyo ensayo titulado, El maestro Tünnermann redescubre al maestro Darío, tomo estas citas: "La obsesión de Carlos --y advierto que todo escritor es obsesivo-- es la de presentar la obra dariana en toda su extensión, en toda su intención. Un largo mural que comprenda todos los matices del poeta vertidos de su pluma en las Ánforas de Epicuro, o mejor trasegarlos en ese "vaso nocturno lleno de dolores, de lejanos recuerdos y desgracias funestas. Diluirlos en un vino de noche, en el maravilloso cristal de las tinieblas."

Es evidente que la Paideia es su tesis central, lo medular, pero, para que esta obra se mantenga en pie es necesario que registre otros referentes y así el estudioso, lector, tenga hasta entonces una visión de conjunto. Que descubra por sí sólo a su primer héroe civil.

(...) No hay tiempo para perder y Carlos acelera su escritura porque la juventud --treinta mil estudiantes, por decir una cifra-- está presta a estudiar todo lo dicho por el maestro Tünnermann, para aprehender nuestra identidad que a las puertas del nuevo milenio continúa sin una clara definición. El pedagogo Carlos redescubre al pedagogo Rubén, a pesar de su credo acrático, y demás advertencias expuestas en el manifiesto de Prosas Profanas.

(...) Anualmente en Nicaragua se le rinde culto a Darío, un culto oficial, seco, sin trascendencia, con programas repetitivos y fatigosos. Las musas proliferan por todas partes con coronas verdes y peplos brillantes, todo festivo como en un baile de máscaras. Ningún libro de Rubén es editado en forma masiva, con la intención que cada estudiante de bachillerato pueda adquirirlo y estudiarlo a fondo. En 1992, a los quinientos años, más que recordar el descubrimiento de América, lo que cabía era hablar de la España descubierta por Rubén Darío, cuando en el texto de España Contemporánea, (1901), el Maestro hace un balance entre lo estrictamente peninsular y la desgraciada vida colonial. 
(...) Ojalá los estudios darianos del doctor Carlos Tünnermann tengan la acogida que verdaderamente merecen. Él, ahora ha venido a colocarse a la cabeza de la bibliografía dariana. Su obra, llena la función primigenia con que fue diseñada y escrita. Él, como lo exigía Goethe, ha podido unir, junto a la belleza literaria, la probidad humana."

Por su parte el ilustre académico, escritor y polígrafo Don Julio Valle Castillo, en su artículo para presentar la obra Valores de la cultura nicaragüense, dimensiona la labor en las humanidades de Don Carlos Tünnermann Bernheim, en estos términos: "El maestro sabe unir y contextualizar en los sesentas estos tres magisterios, los dos magisterios que han orientado a Nicaragua, la poesía y las humanidades. Bien venga este libro sobre los valores nicaragüenses a incrementar los valores nacionales, es decir, ciudadanos. Prosa diáfana, fluyente, que reconoce y entonces señala y al señalar, enseña. Lección de varia dirección, autor que articula su discurso citando a los demás, al otro, algo que no suele practicarse entre nosotros. Visión integradora de la poesía, de las humanidades, de la historia, de la docencia para y en la cultura. Tarea la suya generosa, la generosidad del Dr. Carlos Tünnermann, como diría don Miguel de Unamuno de Reyes, es parte de su inteligencia y ambas, de su bondad. Generosidad, inteligencia y

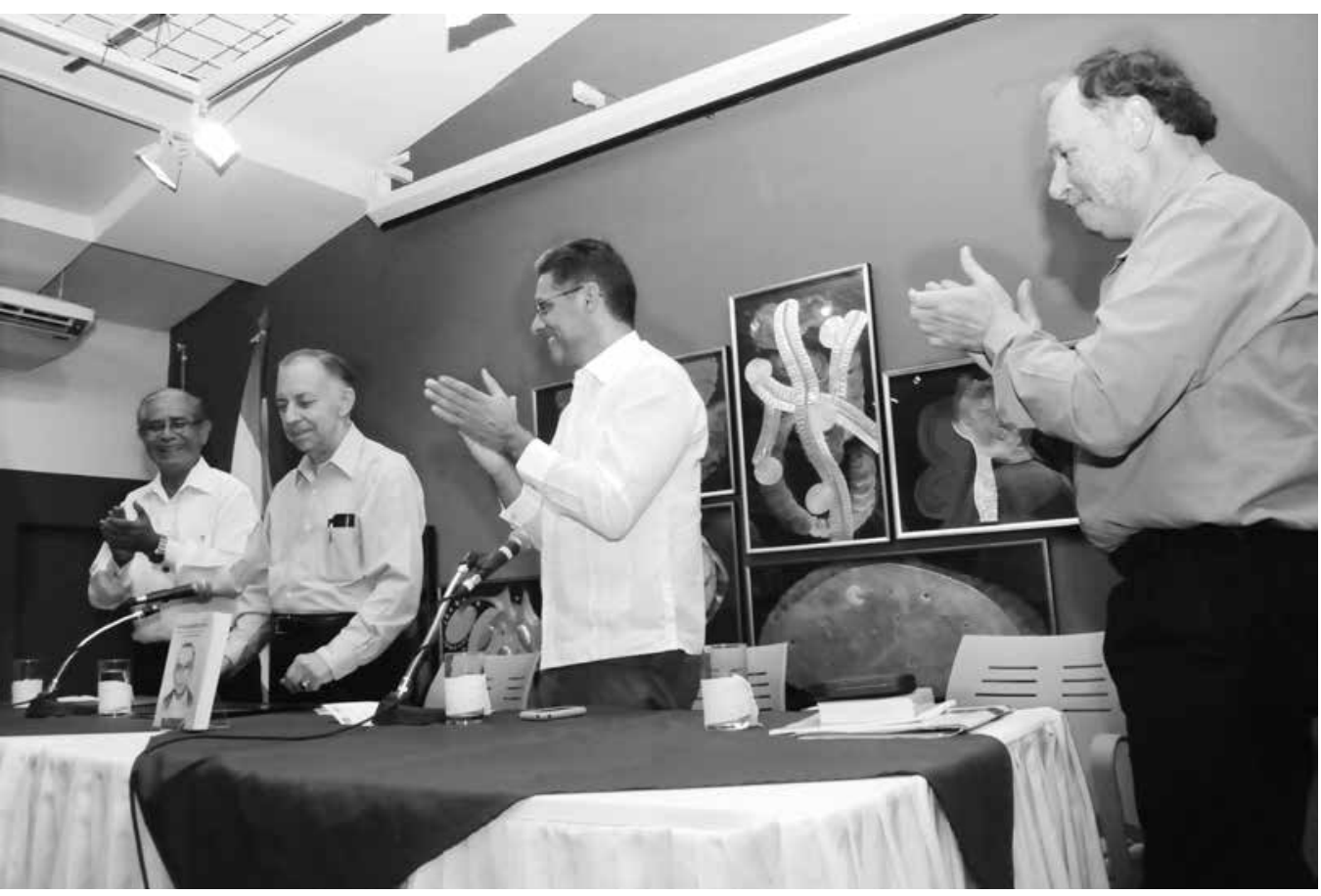

Presiden la mesa, de izquierda a derecha, el Lic. Francisco Arellano, el Dr. Carlos Tünnermann, Ing. René González y el Lic. Anastasio Lovo. bondad, tres palabras o funciones que configuran un Dr. Carlos Tünnermann verdadero, sus valores y los Valores de la cultura nicaragüense."

Ahora nos ocuparemos brevemente del tema que yo llamo el flechazo erótico de la poesía en Carlos Tünnermann Bernheim, puesto en evidencia en su ya célebre libro de poemas, Para construir el amor (PAVSA, Managua, 1998). Sin pretender agotar la abundante bibliografía pasiva que esta joya de nuestra poesía ha provocado, citaré rápidamente algunas opiniones de escritores y críticos profesionales y aficionados que han reaccionado frente al libro Para construir el amor.

Anastasio Lovo, éste vuestro servidor, primero en tiempo primero en derecho, sobre el libro de poemas, Para construir el amor dice: "Es la de Tünnermann una poesía construida en el universo particular y cotidiano de la pareja amorosa, al ritmo vital de una de cal y otra de arena: "De un extremo a otro del día/ de una punta a otra de la noche/ -tú una de cal; yo otra de arena-/ armamos este amor sin adjetivos/ sin otra argamasa/ que su propia sustancia.../"

Así como arma su amor, Tünnermann construye su poesía con pulcritud y transparencia juanramoniana, evitando la adjetivación excesiva, yendo a la sustancia, a la transparencia de imágenes poéticas producto de un equilibrio entre un sentimiento (interior) y una circunstancia (exterior)."

Mi buen amigo, el escritor Don Róger Mendieta Alfaro lanza con precisión esta frase sobre la poesía de Don Carlos: "Poeta del amor comprometido con la inmarcesible sed de amar lo amado. Tünnermann es poeta del amor para el amar, de manera esencial, en las diversas y sublimes formas que el amor y el amar requiere."

Don Ricardo Llopesa, crítico nicaragüense y catedrático en España, nos dice: "Pensé en Horacio, en Catulo, en Ronsard, en Whitman, en Rubén, en Eluard, en Cardenal, en tantos otros, en todos. Pensé que 
Carlos Tünnermann Bernheim es un poeta formidable, de esos que no se dan todos los días, ni de vez en cuando, porque son un raro espécimen, que sabe absorber el pasado y el presente para escribir en futuro.

Miro el entorno que rodea al doctor Tünnermann y veo al nieto de Rubén en su sed de música; veo al hijo de Pablo Antonio en la tensión verbal, y al hermano mayor de Mejía Sánchez y Martínez Rivas porque de ellos fue la palabra precisa."

Mi admirada maestra la Doctora Nydia Palacios Vivas, una crítica literaria calificada e iluminadora, nos advierte: "Lo cierto es que Tünnermann ha pulsado su lira con el dominio de un experto, un excelente poeta, una "rara avis" en esta Nicaragua, sacudida en estas últimas décadas por catástrofes y revoluciones fracasadas, periodo en que ha imperado la poesía panfletaria e inocua. No se equivocó el siempre recordado poeta Pablo Antonio Cuadra cuando afirmó categóricamente: "Cuídese, (a Tünnermann) usted lleva adentro un poeta....yo le vengo siguiendo sus pasos y constantemente encuentro en sus escritos las huellas digitales de la poesía".

Un estudioso de la obra tunnermaniana el Maestro Isidro Rodríguez Silva nos dice sobre la obra: "Carlos Tünnermann Bernheim con su poemario Para construir el amor lleva a su máxima expresión poética, la poesía amatoria y conyugal, en cuanto este poemario, no sólo descubre a un poeta escondido en su yo lírico, sino a un poeta, que a partir del amor, ensancha su poesía hacia la vida misma, en el binomio vida-muerte y al conjunto de poemas que forman Destino y esperanza de la tierra."

Y el escritor Serdán Zelaya nos dice sobre la poesía de Tünnermann: "Para construir el amor", de Carlos Tünnermann es una poesía despojada y directa. De confesiones claras, en ningún momento hay un sesgo por la sugerencia o dejar entrever una posibilidad o duda. Se caracteriza por versos directos y sencillos. Sin retórica ni metáforas desbocadas. Estamos ante una poesía de la necesidad. La necesidad de compartir un hecho genuino y legítimo."

Pero volvamos a la imagen global de Don Carlos Tünnermann Bernheim, mediante ese juego de espejos que Jorge Alvarado Pisani, en su ensayo titulado Una triple introducción al libro Galería de próceres, escritores y educadores, descubre entre el Maestro Edelberto Torres y Don Carlos. He aquí las decidoras y decisivas palabras de Don Edelberto a propósito de Don Carlos: "Por encima de todos sus méritos como educador y como eminente dariano, están las virtudes cívicas del doctor Carlos Tünnermann Bernheim, en grado tal que hacen de él un modelo de ciudadano, de ciudadano para todas las estaciones, un ejemplo de absoluta congruencia entre sus palabras y su conducta. En él nunca hay dobleces, ni contradicciones. Hombre de vida austera, vive siempre muy modestamente y sus únicas riquezas son su sabiduría, sus excelsas virtudes y su familia. La vida y obra del doctor Carlos Tünnermann Bernheim es uno de los pocos ejemplos que en estos tiempos podemos mostrar a la juventud actual, que con razón grita su desengaño, su escepticismo, ante la casi total ausencia en nuestra vida política de personalidades cuya honestidad sea a toda prueba, cuyo carácter tenga el temple del carácter del doctor Tünnermann, y cuyo desinterés y dedicación al bien común puedan compararse en algún grado a ese arquetipo de ciudadano probo y rectilíneo que siempre ha sido, es y será el Maestro y Doctor Carlos Tünnermann Bernheim."

Antes de terminar quiero dejar constancia que otras facetas del diamante sólo están someramente contenidas en esta Valoración Múltiple, como lo son su labor periodística, su desempeño diplomático y su acción ético-política. Esta Valoración Múltiple debe ser sólo la primera de una serie que desarrolle la inmensa tarea de ponderar una obra de extraordinaria valía para nuestra identidad cultural.

Cierro esta intervención con un gran abrazo para mi Maestro Doctor Carlos Tünnermann Bernheim, con el regocijo de haber vislumbrado alguna luz de este vivo diamante de la cultura nicaragüense, latinoamericana y mundial. ¡Felicidades Maestro! En nombre de los escritores y las escritoras nicaragüenses y de todos nuestros compatriotas le digo: Maestro Tünnermann Bernheim:jGracias por su magna obra!

Un querido amigo suyo, de quien no dudo está con nosotros en este momento, escribió en su honor este poema que como broche de oro quiero leer para culminar mis palabras. 
Al Prof. Carlos Tünnermann Bernheim, que trabaja incansablemente a favor de la paz, la concordia y la justicia.

Hoy, día 15 de febrero del año 2003,

clamor mundial, por fin,

de voces de la gente.

Por fin,

la democracia entera.

Por fin,

el pueblo,

en las carteleras

de todos los diarios

de la Tierra.

Por fin,

la esperanza

de paz y de justicia.
La palabra, al fin, y no la espada

(aunque, después de oírnos, no escucharon nuestras súplicas y estalló la guerra

basada en la mentira...).

Pronto seremos muchos más, y prevalecerá la voz sobre la fuerza.

Federico Mayor Zaragoza

Madrid, 15 de febrero de 2003.

Muchas gracias por su heroica atención. Managua, 25 de abril de 2013.

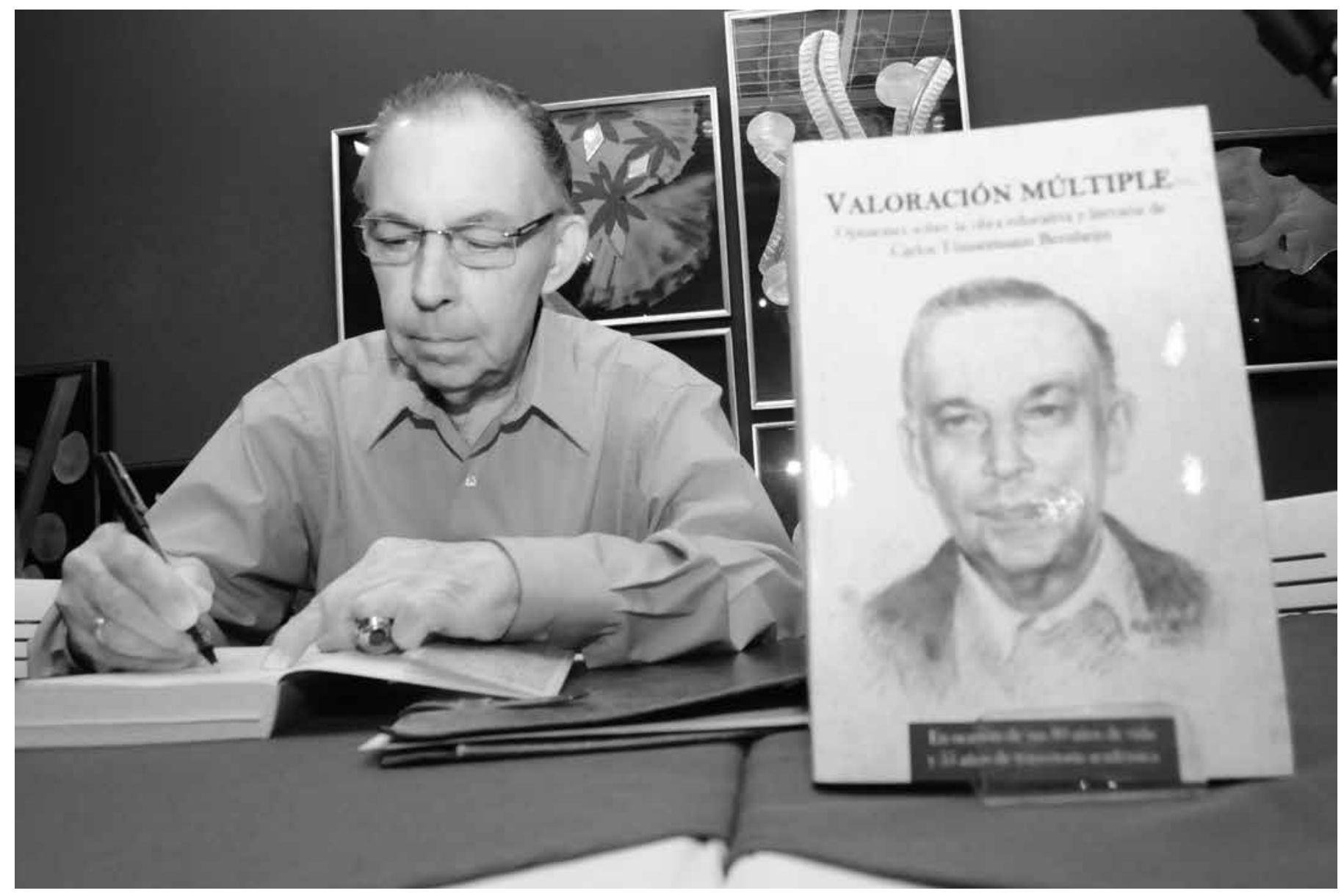

El Dr. Carlos Tünnermann firmando autógrafos. 